Bull. Chem. Soc. Ethiop. 2020, 34(1), 203-214.

ISSN 1011-3924

(c) 2020 Chemical Society of Ethiopia and The Authors

Printed in Ethiopia

DOI: https://dx.doi.org/10.4314/bcse.v34i1.19

\title{
INFLUENCE OF NiO NANO-FLAKES DISPERSION ON THE VISCOSITY OF LUBRICATING OIL
}

\author{
C. Mathalai Sundaram*, A. Vembathu Rajesh and V. Sivaganesan
}

Department of Mechanical Engineering, Nadar Saraswathi College of Engineering and Technology, Vadapudupatti, Theni-625531, India

(Received July 1, 2019; Revised November 8, 2019; Accepted November 21, 2019)

\begin{abstract}
Protecting interacting surfaces of mechanical systems against friction and wear have a wide range of industrial applications. Viscosity is the supreme property of any lubricant which overpowers viscous drag in hydro-dynamically lubricated mechanical systems. The dispersion stability of NiO-nanolubricants is achieved by ultrasonication technique. The detailed study of the viscosity of NiO nano-flakes dispersed in SN500 lubricants with weight fraction of $0.25-1.5 \%$ was performed in the temperature between $40-90{ }^{\circ} \mathrm{C}$. The results show that increasing the weight fraction of $\mathrm{NiO}$ nano-flakes resulted in consistence viscosity increment. Further, the measured viscosity is compared with different concentration and temperature dependent theoretical models. On the basis on experimental viscosity data a theoretical correlation is recommended to predict the viscosity of $\mathrm{NiO}$ nanolubricants with less than $5 \%$ margin of deviation.
\end{abstract}

KEY WORDS: Viscosity, Nano-flakes, Nanolubricants, Nickel oxide, Ultrasonication, Margin of deviation

\section{INTRODUCTION}

Protecting interacting surfaces of mechanical systems against friction and wear have a wide range of industrial applications. Lubricants are designed to provide a protective film that condenses friction and wear of interacting surfaces in relative motion, protect them against corrosion and reduce the consumption of energy. The requirements of good liquid lubricants are the resistance to low foaming tendency, aging, oxidation, good load-carrying capacity and significant viscosity-temperature behavior [1]. The enhanced viscosity of liquid lubricants will increase the ability of the oil film to stick for longer time period providing a superior protection against friction and wear [2].

Further application of nanotechnology measures a new passive way to explore this topic in detail. Researchers have proven that nanoparticle dispersions into the water or liquid lubricants not only have the advantages of superior thermo-physical properties, but also provide enhanced tribological properties due to the decrease in friction coefficient and superior anti-wear possessions [3]. The nanoparticles has increased relative surface area and quantum effects which significantly alter the physical, optical, electrical, chemical magnetic and mechanical behavior of liquid lubricants when it is homogeneously dispersed [4]. Many authors utilized nanotechnology to enhance the viscosity of liquid lubricants [5-13].

Generally, viscosity decreases with increasing the temperature for all types of liquid lubricants, nanofluids and nanolubricants. Nanolubricants are colloidal dispersions of nanometer-sized materials $(1-100 \mathrm{~nm})$ such as nanoparticles, nanotubes, nanorods, nanofibers, nanosheets and nanowires into conventional liquid lubricants [14]. Nanolubricants were initially industrialized to decrease engine wear through the "ball bearing" effect [15]. The type of nanoparticle, shape, size and the amount of surfactant used affects the thermo-physical properties of any nanolubricants [16]. Ijam et al. [17] experimentally investigated the thermophysical properties of grapheme oxide nano-sheets suspended indeionized water/ethylene glycol

*Corresponding author. E-mail: cmathalaisundaram@gmail.com

This work is licensed under the Creative Commons Attribution 4.0 International License 
(DW/EG) with a weight fraction of $0.01-0.10 \%$ and temperature of $25-45{ }^{\circ} \mathrm{C}$. The results show that the viscosity of $0.10 \mathrm{wt} . \% \mathrm{DW} / \mathrm{EG}$ nanofluid is enhanced by $35 \%$ due to the dispersion of graphene oxide nano-sheets compared to the base fluid at $20{ }^{\circ} \mathrm{C}$ and it is reduced by $48 \%$ with increasing the temperature in the range of $20-60{ }^{\circ} \mathrm{C}$ [17]. Attari et al. [18] studied the effects of temperature and mass fraction of $\mathrm{NiO}, \mathrm{TiO}_{2}, \mathrm{ZnO}, \mathrm{Fe}_{2} \mathrm{O}_{3}$ and $\mathrm{WO}_{3}$ nanoparticles on viscosity of nanolubricants and their experimental results show that the increment of temperature decreases the viscosity of the nanolubricants [18]. On the contrary, Chen et al. [19] reported that the relative viscosity is independent of temperature due to insignificant Brownian diffusion in comparison to convection in high shear flows [19].

For the same nanoparticle aspect ratio and size, the consequence of the non- spherical particles on the viscosity was superior in comparison to the spherical nanoparticles [20]. In this study, viscosity of NiO-nanolubricants were experimentally examined with the weight fraction of $(0.25-1.5) \%$ and temperature in between $(40-90){ }^{\circ} \mathrm{C}$ in absence of surfactants. The $\mathrm{NiO}$ nano-flakes were prepared by sol-gel technique. The chemical constituents, size and morphology were evaluated by EDS, XRD and SEM. Different weight fractions of NiOnanolubricants were prepared by dispersing NiO nano-flakes into SN500 lubricant. The dispersion stability of NiO-nanolubricants is achieved by ultrasonication technique. The viscosity of SN500 lubricant and different concentrations of NiO-nanolubricants is estimated using Brookfield LVDVE digital viscometer. The measured viscosity of NiO-nanolubricants is being compared with the predicted values acquired from the existing additive concentration and temperature dependent theoretical models.

\section{EXPERIMENTAL}

\section{Preparation and characterization of NiO flakes}

The NiO flakes were synthesized through sol-gel method in which sodium hydroxide is mixed with nickel acetate tetrahydrate at room temperature [21-22]. The solution is agitated continuously for 2 hour and then it is dried in a furnace at $500{ }^{\circ} \mathrm{C}$ for 2 hours. The EDS spectrum, XRD spectrum and the SEM morphology of the resulting dark green powder is shown in Figure 1.

The EDS spectrum of the sol-gel by-product is represented in Figure 1(a) which confirms the presence of Ni and $\mathrm{O}$-atoms in the lattice without any impurities. The XRD pattern of $\mathrm{NiO}$ particles is shown in Figure 1(b) the distinct diffraction peaks which is in accordance with the standard JCPDS No-65-5745 [23-32]. The diffraction peaks are indexed with (111), (200), (220), (311), (222) and (400) respective planes with the lattice constant value of $4.1788 \AA$. It confirms that the prepared $\mathrm{NiO}$ particles have face center cubic (FCC) structure and any other secondary phase related peaks is not observed. Further, the crystallite size of the NiO particles is estimated from the dominant peak using Scherrer formula [33]. The calculated value is 72.97 $\mathrm{nm}$ and the nano-crystalline morphology of NiO is studied by SEM (Figure 1(c) and Figure 1(d)). The particles have quite flat surface texture and the morphology of $\mathrm{NiO}$ particles appears as flakes which are stacked one above the other due to great surface energy.

\section{Preparation of $\mathrm{NiO}$-nanolubricants}

The NiO nano-crystalline flakes of size $72.97 \mathrm{~nm}$ were dispersed into SN500 lubricant by digital probe sonication at room temperature. The preparation footsteps of NiO-nanolubricant with different additive concentration are as follows: $250 \mathrm{~mL}$ of SN500 lubricant is taken in a $300 \mathrm{~mL}$ beaker. Required weight percentage of $\mathrm{NiO}$ nano-crystalline flakes of size $72.97 \mathrm{~nm}$ is dispersed into SN500 lubricant at room temperature. Continuously sonicate at $20 \mathrm{kHz}$ for $20 \mathrm{~min}$ by the digital probe ultrasonicator. 

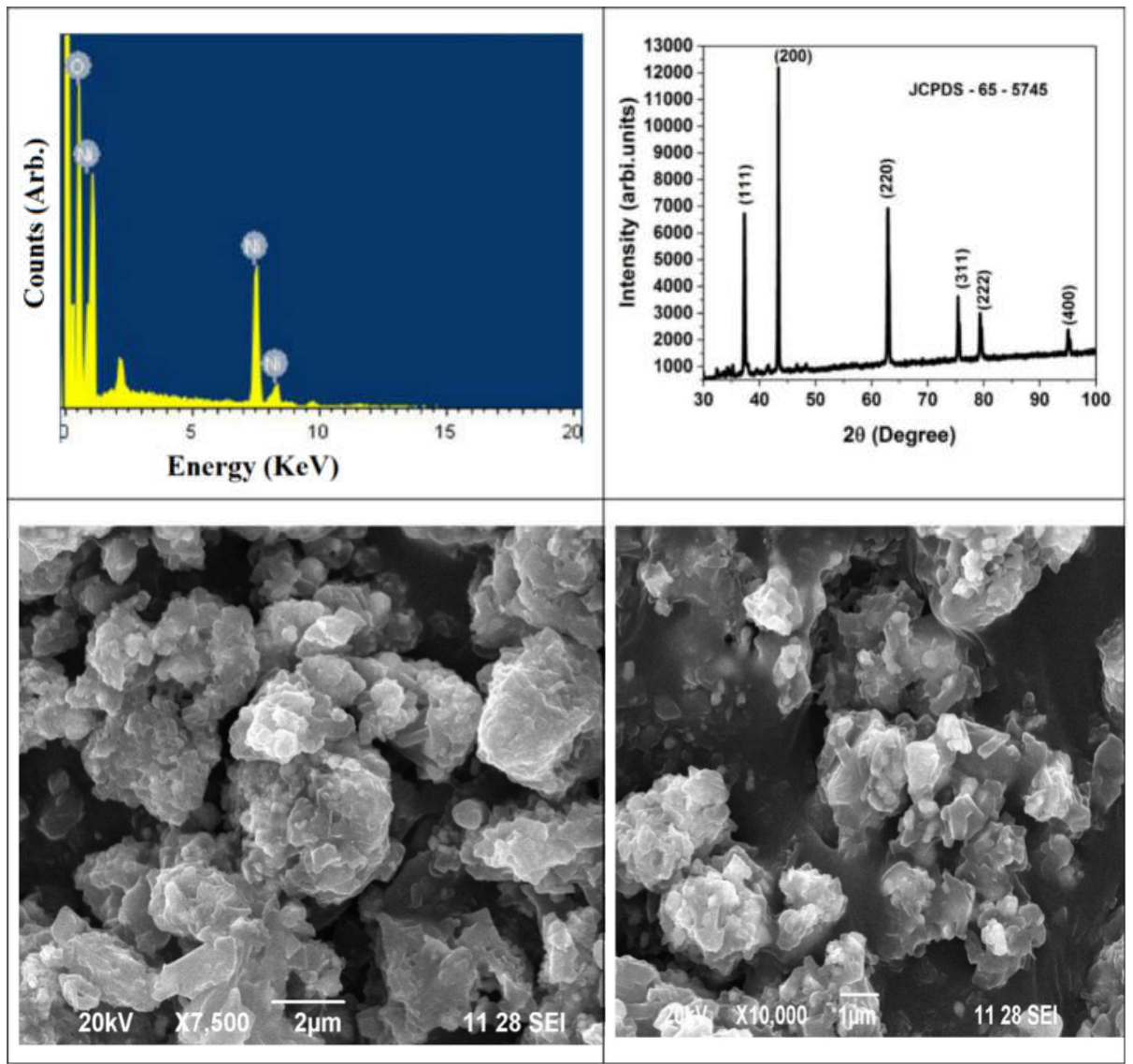

Figure 1. Characterisation of NiO flacks, (a) EDS spectrum, (b) XRD spectrum and (c) SEM morphology.

Viscosity measurements

The viscosity of SN500 lubricant and different concentrations of NiO-nanolubricants is estimated using Brookfield LVDVE digital viscometer, USA. It is a rotating type viscometer in which the torque required to turn the fluid medium is calibrated to the viscosity of liquid at a known spindle speed.

\section{RESULTS AND DISCUSSION}

The viscosity of the SN500 lubricant and NiO-nanolubricants are investigated in temperature range of $40{ }^{\circ} \mathrm{C}$ to $90{ }^{\circ} \mathrm{C}$ and weight fraction of $(0.25-1.5) \%$. The viscosity of $\mathrm{NiO}$ nanolubricants is examined with different weight fraction as shown in Figure 2. It is found from the graph that the viscosity is enhanced almost linearly with increasing all weight fractions of $\mathrm{NiO}$ nano-flakes. This enhancement is due to the large surface area of $\mathrm{NiO}$ nano-flakes which increases the effort to resist the moment of the molecules of SN500 lubricant and elevates the internal shear stress during fluid movement. This resistance is more at higher weight fractions of 
NiO nano-flakes in SN500 lubricant. Hence, the viscosity increases with increasing the weight fraction under the same size of $\mathrm{NiO}$ nano-flakes. Further, the increase in concentration of $\mathrm{NiO}$ nano-flakes in SN500 lubricant leads to more interaction between them in the unit volume of $\mathrm{NiO}$-nanolubricants. The NiO have large surface area which has large effect on the suspension viscosity under increased solid phase volume fraction due to the dispersion of solid additives.

At low nano-flakes concentration, interaction between the dispersed nano-flakes is less and the probability of interaction and contact among the dispersed additives is less as it has enough gaps to overcome the large surface energy. The increase in the concentration enhances the probability of interaction between them and surface area plays vital role in it. The interaction develops agglomeration which may have lamellar structured oil molecules-additive materials and agglomerated $\mathrm{NiO}$ nano-flakes. It increases the flow resistance and the possibility $\mathrm{NiO}$ nano-flakes to settle down.

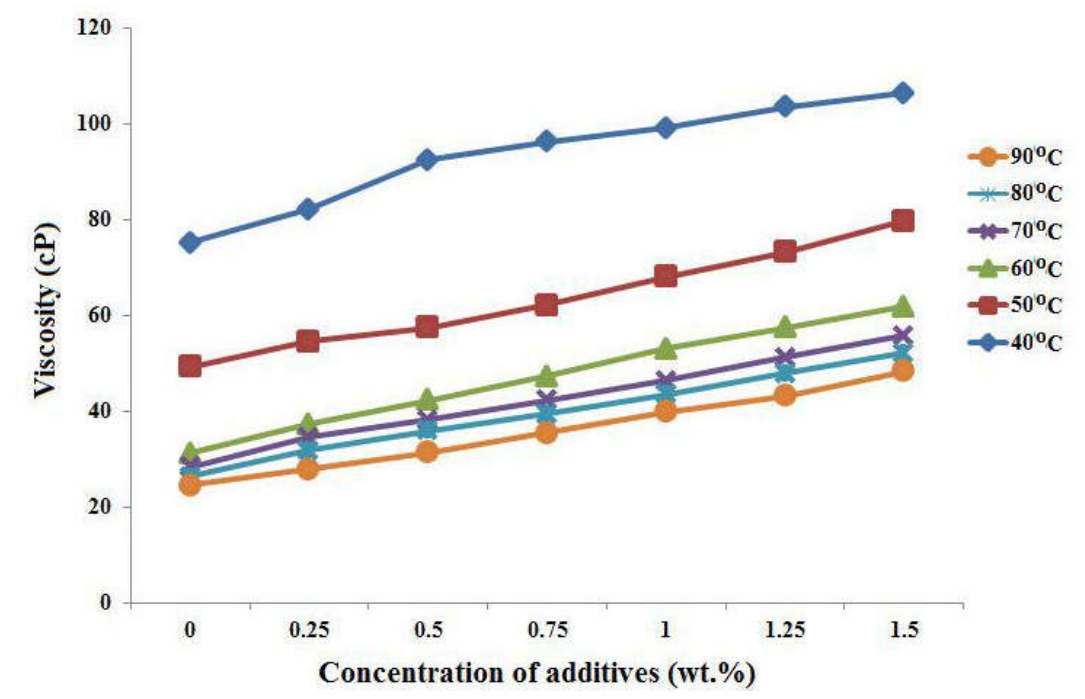

Figure 2. The viscosity of nanolubricants with different weight fraction of $\mathrm{NiO}$ nano-flakes.

The percentage of viscosity enhancement of NiO-nanolubricants is estimated by the following formula:

Viscosity enhancement $=\left\lfloor\frac{\text { Viscosity of nanolubricant-Viscosity of basefluid }}{\text { Viscosity of basefluid }}\right\rfloor \times 100$

The percentage of viscosity decrement of SN500 lubricant and different concentrations of NiOnanolubricants is estimated by the following formula:

Viscosity decrement $=\left\lfloor\frac{\text { Viscosity of basefluid - Viscosity of nanolubricant }}{\text { Viscosity of basefluid }}\right\rfloor \times 100$

Further, the enhancement in viscosity of SN500 lubricant due to the dispersion of nanomaterials has been reported by other authors. For example, Maheswaran et al. [34] studied the viscosity of garnet-SN500 lubricant oil nanofluid with a volume fraction of $(0.25-0.75) \%$ and temperature range from $30{ }^{\circ} \mathrm{C}$ to $75{ }^{\circ} \mathrm{C}$. They reported a dramatic enhancement of dynamic viscosity at $75{ }^{\circ} \mathrm{C}$ from $16.40 \mathrm{cP}$ to $32.93 \mathrm{cP}$ due to the dispersion of $0.75 \mathrm{wt} \%$ of garnet nanoparticles [34]. The 
relationship between the additive concentration and the functional temperature of different additive concentration of NiO-nanolubricants is shown in Figure 3.

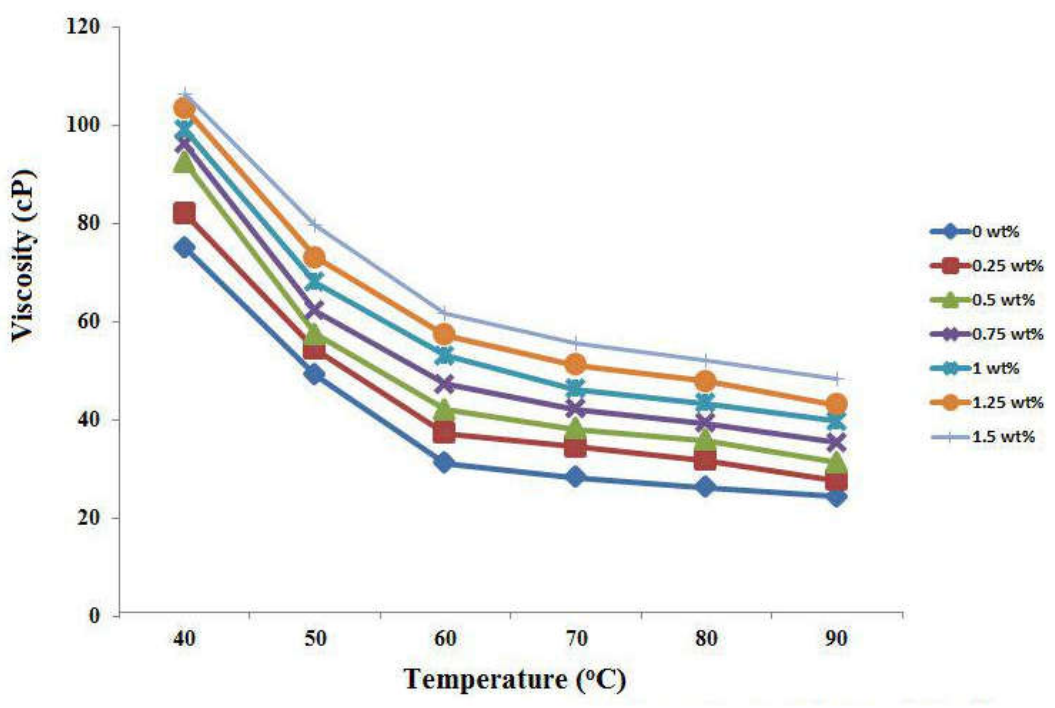

Figure 3. Effect of temperature on the viscosity NiO-nanolubricants.

Figure 3 demonstrates the relationship of the kinematic viscosity of the NiO-nanolubricants and the temperature at different weight fractions. It depicts that the viscosity of SN500 lubricant and NiO-nanolubricants falls exponentially with increasing temperature. For example, the viscosity of SN500 lubricant is diminished quickly by $34.44 \%, 58.51 \%, 62.36 \%, 65.03 \%$ and $67.42 \%$ when the temperature was increased from $40{ }^{\circ} \mathrm{C}$ to $90{ }^{\circ} \mathrm{C}$, in successive steps of $10{ }^{\circ} \mathrm{C}$ each time. The viscosity of $0.25 \mathrm{wt} \%$ of NiO-nanolubricant falls quickly by $33.61 \%, 54.57 \%$, $57.86 \%, 61.27 \%$ and $66.14 \%$ during the same temperature range. The increment in temperature causes the weakening of intermolecular adhesion forces, affect the particle migration, decreases the internal shear stress and diminishes the average intermolecular forces of SN500 lubricant and different concentrations of NiO-nanolubricants. Also, it deteriorates the forces between subatomic molecules as the temperature get increases. The weakening of intermolecular adhesion forces enhances the probability of interaction between the NiO nano-flakes in SN500 lubricant where increase in concentration results in more interaction between them due to surface energy and the Brownian motion of the homogeneously dispersed nano-flakes.

Hence, the viscosity of NiO-nanolubricants and its dispersion stability with time and measured temperature range are the significant parameters for any heat transfer and lubrication application. The increase in nanoparticle concentration causes an attraction between the $\mathrm{NiO}$ nano-flakes, which results with time clustering and thus inhomogeneity in the prepared NiOnanolubricants at high temperature and high nanoparticle concentrations. At low temperature and low nano-flake concentration, the strong intermolecular strength resists additive-additive interaction which overcomes the possibility of agglomeration and sedimentation. Therefore, the viscosity of SN500 lubricant and all concentrations of NiO-nanolubricants decrease with increasing operating temperature. The relationship between the additive concentration, functional temperature and viscosity enhancement of different additive concentration of $\mathrm{NiO}$ nanolubricants are shown in Figure 4 . At $40{ }^{\circ} \mathrm{C}$ the viscosity of SN500 lubricant enhances from $75.2 \mathrm{cP}$ to $82.1 \mathrm{cP}, 92.5 \mathrm{cP}, 96.3 \mathrm{cP}, 99.2 \mathrm{cP}, 103.5 \mathrm{cP}$ and $106.4 \mathrm{cP}$ due to the homogeneous 
dispersion of 0.25 wt. $\%, 0.50$ wt. $\%, 0.75$ wt. $\%, 1$ wt. $\%, 1.25$ wt. $\%$ and 1.50 wt. $\%$ of $\mathrm{NiO}$ nanoflakes, respectively, in which the obtained viscosity enhancement is $9.18 \%, 23 \%, 28.06 \%$, $31.91 \%, 37.62 \%$ and $41.49 \%$. This phenomenon was particularly expected at high solid phase volume fraction.

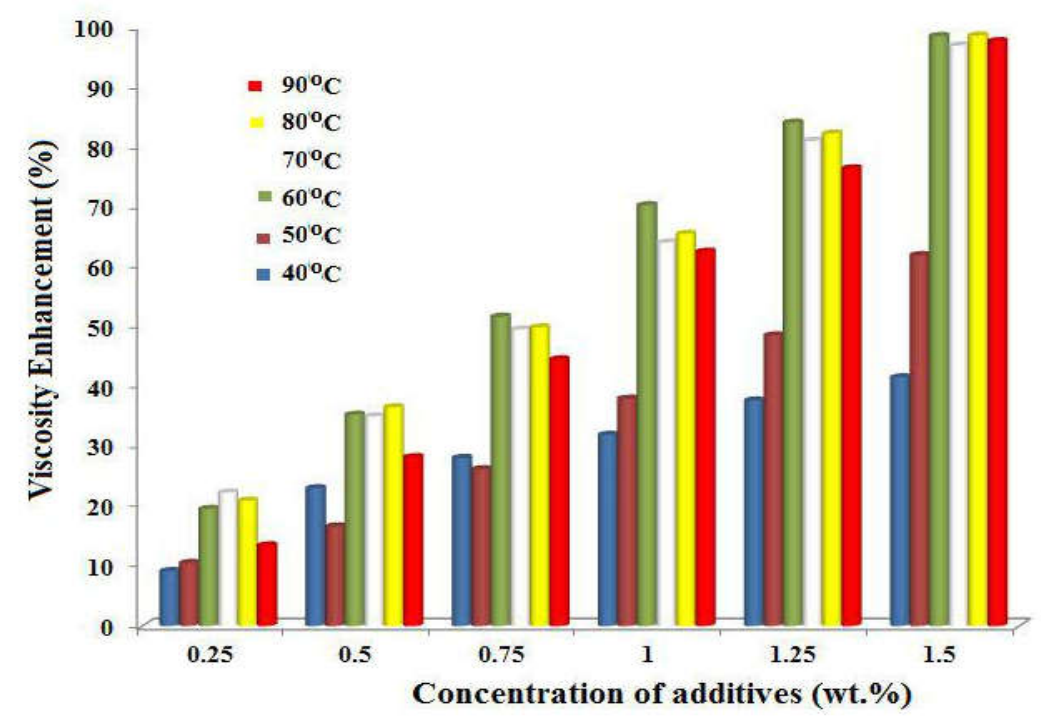

Figure 4. Viscosity enhancements of NiO-nanolubricants.

Further, the experimentally measured viscosities of NiO-nanolubricants are compared with the theoretical equations proposed by other investigators. In theoretical perspective, the thoughtful understanding of viscosity of nanolubricants is a challenging task as it does not behave precisely the similar to the ordinary two-phase fluid. Einstein [35] proposed a theoretical correlation to approximate the viscosity of a fluid containing low concentration of spherical particles as below:

$\mu_{\mathrm{nf}}=\mu_{\mathrm{bf}}(1+2.5 \Phi)$

Hatschek [36] developed the following model to estimate the viscosity of two-phase systems comprising up to $40 \%$ concentration of dispersed particles.

$\mu_{\mathrm{nf}}=\mu_{\mathrm{bf}}(1+4.5 \Phi)$

Batchelor [37] reported a theoretical correlation (Equation) to calculate the viscosity of nanofluids by considering the effect of Brownian motion of the homogeneously dispersed nanoparticles.

$\mu_{\mathrm{nf}}=\mu_{\mathrm{bf}}\left(1+2.5 \Phi+6.2 \Phi^{2}\right)$

Nguyen et al. proposed the following theoretical Arrhenius type correlations for computing the viscosity of $\mathrm{Al}_{2} \mathrm{O}_{3}$-nanofluids [38]:

$\mu_{\mathrm{nf}}=\mu_{\mathrm{bf}} \times 0.904 \mathrm{e}^{0.1483 \Phi}$
$\mu_{\mathrm{nf}}=\mu_{\mathrm{bf}}\left(1+0.025 \Phi+0.015 \Phi^{2}\right)$ 
Nguyen et al. proposed the following theoretical Arrhenius type correlations to determine the viscosity of CuO-nanofluids [38]:

$\mu_{\mathrm{nf}}=\mu_{\mathrm{bf}}\left(1.475-0.319 \Phi+0.051 \Phi^{2}+0.009 \Phi^{3}\right)$

Ijam et al. [17] developed a theoretical correlation with less than $2 \%$ of standard deviation to estimate the nanoparticle concentration dependent viscosity of graphene oxide nano sheetsDW/EG nanofluids based on the fitting with the experimental data:

$\mu_{\mathrm{nf}}=\mu_{\mathrm{bf}}(1+343 \Phi)$

Wang et al. [39] proposed a theoretical correlation to estimate the nanoparticle concentration dependent viscosity of nanofluid:

$\mu_{\mathrm{nf}}=\mu_{\mathrm{bf}}\left(1+7.3 \Phi+123 \Phi^{2}\right)$

Pak and Cho have experimentally investigated the viscosity of $\mathrm{Al}_{2} \mathrm{O}_{3}$ and $\mathrm{TiO}_{2}$ nanofluids and they summarized the following particle size and concentration dependent viscosity equation [40]:

$\mu_{\mathrm{nf}}=\mu_{\mathrm{bf}}\left(1+39.11 \Phi+533.9 \Phi^{2}\right)$

Tseng and Lin developed the following expression to predict the viscosity of $\mathrm{TiO}_{2}$ nanofluids based on experimental data fitting [41]:

$\mu_{\mathrm{nf}}=\mu_{\mathrm{bf}} \times 13.47 \mathrm{e}^{35.98 \Phi}$

According to the Einstein theoretical model, Roscoe et al. developed a nanoparticle concentration dependent equation to estimate the viscosity of nanofluid [42]:

$\mu_{\mathrm{nf}}=\mu_{\mathrm{bf}}(1-\Phi)^{-2.5}$

Redhwan et al. investigated the thermos-physical properties of $\mathrm{SiO}_{2}$-polyalkylene glycol nanolubricants and proposed a theoretical equation to estimate their viscosity in the temperature range of $303 \mathrm{~K}$ to $353 \mathrm{~K}[43]$ :

$$
\frac{v_{N L}}{v_{L}}=21\left[\left(1+\frac{\phi}{100}\right)^{0.67}\left(0.1+\frac{T-273}{80}\right)^{0.013}\right]
$$

The experimentally obtained temperature dependent viscosity of NiO-nanolubricants has been compared with the theoretical equations proposed by other investigators. Nguyen et al. proposed the following theoretical correlation to estimate the viscosity of nanofluids by considering the influence of nanoparticle concentration and operating temperature [44]:

$\mu_{\mathrm{nf}}=\mu_{\mathrm{bf}}(1.1250-0.007 \mathrm{~T})$

Yiamsawas et al. proposed the following correlation to compute the viscosity of the EG-water mixture [45]:

$\mu_{\mathrm{nf}}=\mu_{\mathrm{bf}}\left(0.0003 \mathrm{~T}^{2}-0.0461 \mathrm{~T}+2.3775\right)$

Zawawi et al. reported the following correlation to determine the nanoparticle concentrations and temperature dependent viscosity of nanolubricant with $\pm 5 \%$ of standard deviation [46]:

$\mu_{n f}=\left[1+\frac{\emptyset}{100}\right]^{66}\left[0.1+\frac{T}{353}\right]^{0.02}$

Esfe et al. investigated the rheological behavior of ZnO-MWCNT/10W40 engine oil nanofluids at the temperatures between $5-55^{\circ} \mathrm{C}$. They proposed the following correlation to forecast the 
dynamic viscosity of nanolubricants in terms of nanoparticle concentration, temperature and dynamic viscosity [47]:

$\frac{\mu_{n f}}{\mu_{b f}}=1.035+\frac{\emptyset e^{-1.023 \varnothing\left[2.046 \frac{\emptyset}{T}+0.4015 \emptyset^{2} T\right]}}{T^{0.8441}}$

The margin of deviations of the predicted viscosity values are determined by the following equation.

$$
\text { Margin of deviation }=\left[\frac{\left(\frac{\mu_{n f}}{\mu_{b f}}\right)_{E x p}-\left(\frac{\mu_{n f}}{\mu_{b f}}\right)_{T h e}}{\left(\frac{\mu_{n f}}{\mu_{b f}}\right)_{E x p}}\right] \times 100
$$

The experimentally obtained viscosity values are compared with the following theoretical correlations Einstein [35], Hatschek [36], Batchelor [37], Nguyen et al. [38], Ijam et al. [17], Wang et al. [39], Pak and Cho [40], Tseng and Lin [41], Roscoe et al. [42], Redhwan et al. [43], Yiamsawas et al. [45], Zawawi et al. [46] and Esfe et al. [47] as shown in Figure 5.

It is clear from the Figure 5 that the above theoretical correlations failed to provide an accurate estimation for the measured viscosity of NiO-nanolubricants due to difference in measurement techniques, surface chemistry, morphology, and shear rate, etc., especially when the solid phase volume fraction reached above $0.5 \mathrm{wt} \%$, and the margin of deviations becomes prominent. The viscosity values estimated by Einstein [35], Hatschek [36], Batchelor [37], Ijam et al. [17], Wang et al. [39], Pak and Cho [40], Tseng and Lin [41], Roscoe et al. [42] and Redhwan et al. [43], theoretical correlations show anomalous hike. These models determined the viscosity values based on the weight fraction of dispersed nano-flakes, while ignoring other parameters such as particle size, operating temperature, particle shape, density even the effect of Brownian motion is not taken into consideration. Hence, it becomes highly necessary to build the theoretical model which can consider and can account for the effect of other factors that affects the viscosity.

The temperature dependent theoretical correlations are reported by Nguyen et al. [38], Yiamsawas et al. [45] and Zawawi et al. [46]. In these correlations the effect of nanoparticle weight fraction is not considered. Nguyen et al. [38] reported a theoretical correlation to estimate the viscosity of $\mathrm{CuO}$-nanofluids. The viscosity value obtained by this equation decreases with increment of the weight fraction of $\mathrm{NiO}$ nano-flakes. At $40{ }^{\circ} \mathrm{C}$, the margin of deviations of the predicted viscosity values by Zawawi et al. [46] is $4.7 \%$ whereas it increases with the increase of weight fraction. The margin of deviations of the predicted viscosity values by Esfe et al. [47] varies from $4.38 \%$ to $9.96 \%$ when the weight fraction of the NiOnanolubricants changes from $0.25 \mathrm{wt} \%$ to $1.50 \mathrm{wt} \%$ at $40{ }^{\circ} \mathrm{C}$ temperature whereas it varies from $5.5 \%$ to $2.8 \%$ when the weight fraction of the $\mathrm{NiO}$-nanolubricants varies from $0.25 \mathrm{wt} \%$ to 1.50 $\mathrm{wt} \%$ at $50{ }^{\circ} \mathrm{C}$ temperature.

Hence, the theoretical correlation of Esfe et al. [47] can be used to predict the viscosity of $\mathrm{NiO}$ - nanolubricants up to $0.50 \mathrm{wt} \%$ of $\mathrm{NiO}$ nano-flakes and up to $50{ }^{\circ} \mathrm{C}$ temperature. According to the comparison, the margin of deviations of the predicted viscosity values by Zawawi et al. [46] is less than 5\% when the weight fraction of the NiO-nanolubricants varies from $0.25 \mathrm{wt} \%$ to $1 \mathrm{wt} \%$ in the measured temperature range. Hence, this model was used for estimating the viscosity of the NiO-nanolubricants because of its better agreement with the experiment data. 


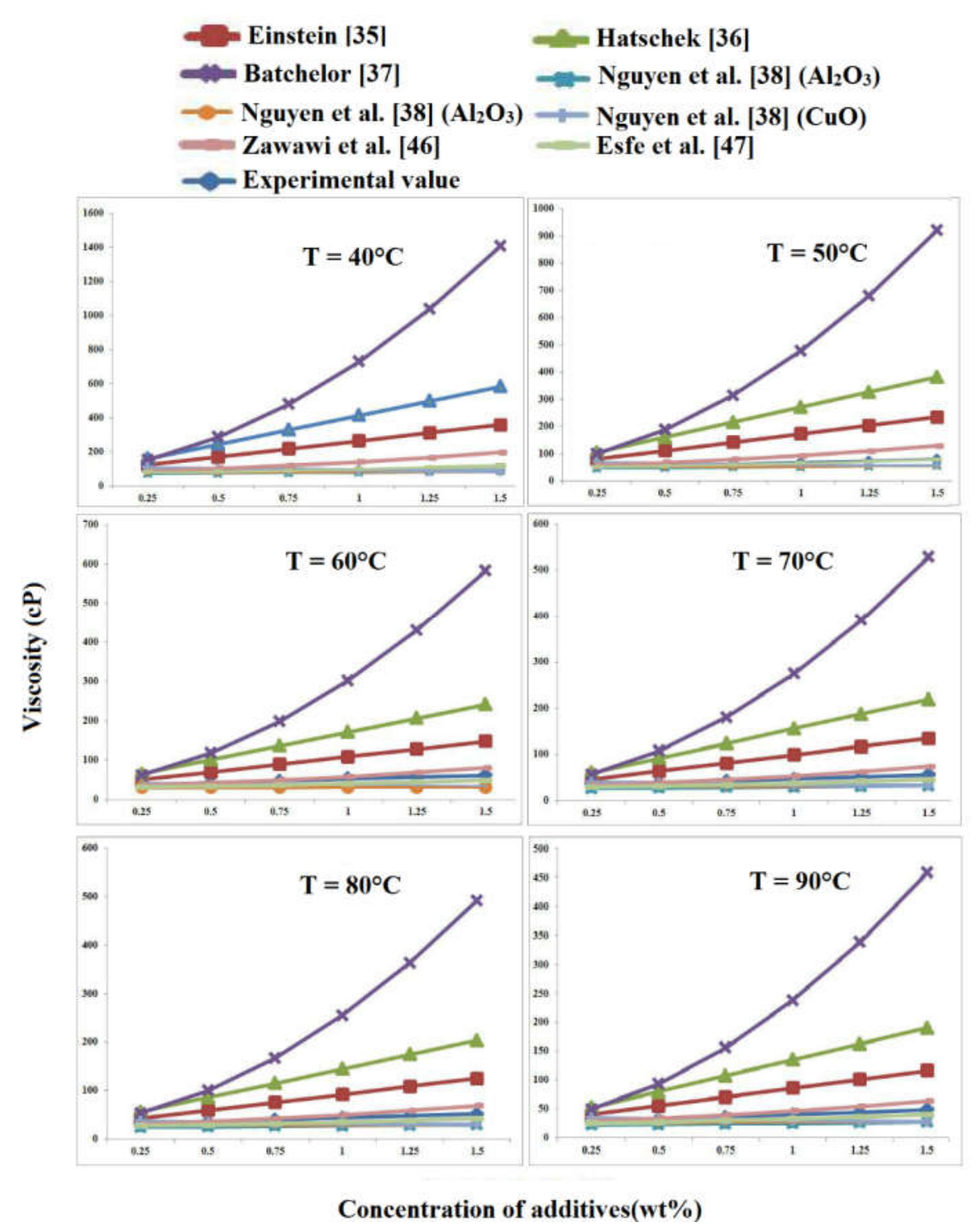

Figure 5. The viscosity of nanolubricants predicted by different theoretical models.

\section{CONCLUSIONS}

In this study, the factors that affect the viscosity were discussed which includes temperature, particle size, shape and aspect ratio of the dispersed particles. The NiO nano-flakes are prepared by sol-gel technique. The chemical constituents, size and morphology are evaluated by EDS, XRD and SEM. Different weight fractions of NiO-nanolubricants were prepared by dispersing NiO nano-flakes into SN500 lubricant. The viscosity results showed that increasing the weight 
fraction of $\mathrm{NiO}$ nano-flakes resulted in significant viscosity enhancement and it was further compared with different theoretical models. The theoretical correlation of Zawawi et al. [46] can be used to predict the viscosity of NiO-nanolubricants up to $0.25 \mathrm{wt} \%$ of $\mathrm{NiO}$ nano-flakes and up to $40{ }^{\circ} \mathrm{C}$ temperature. The theoretical correlation of Esfe et al. [47] can be used to predict the viscosity of $\mathrm{NiO}$-nanolubricants up to $0.50 \mathrm{wt} \%$ of $\mathrm{NiO}$ nano-flakes and up to $50{ }^{\circ} \mathrm{C}$ temperature whereas the theoretical correlation of Zawawi et al. [46] can be used to predict the viscosity within less than $5 \%$ of margin of deviation.

\section{REFERENCES}

1. Nullig, M; Peters, F. Experiments on the mass transfer of gas bubbles in mineral oil. Colloid. Surface A 2018, 540, 81-89.

2. Chon, C.; Kihm, K. Thermal conductivity enhancement of nanofluids by Brownian motion. Int. J. Heat Transfer. 2005, 127, 810-816.

3. Mursheda, S.M.S.; Estelle, P. A state of the art review on viscosity of nanofluids. Renew. Sust. Energ. Rev. 2017, 76, 1134-1152.

4. Ijam, R.; Saidur, P.; Ganesan, A.; Golsheikh, M. Stability, thermo-physical properties, and electrical conductivity of graphene oxide- deionized water/ethylene glycol based nanofluid. Int. J. Heat Mass Tran. 2015, 87, 92-103.

5. Azmi, W.H.; Sharma, K.V.; Mamat, R.; Najafi, G.; Mohamad, M.S. The enhancement of effective thermal conductivity and effective dynamic viscosity of nanofluids - a review. Renew. Sust. Energ. Rev. 2016, 53, 1046-1058.

6. Bashirnezhad, K.; Bazri, S.; Safaei, M.R.; Goodarzi, M.; Dahari, M.; Mahian, O.; Dalkılıça, A.S.; Wongwises, S. Viscosity of nanofluids: A review of recent experimental studies. Int. Commun. Heat Mass. 2016, 73, 114-123.

7. Eiamsa-ard, S.; Kiatkittipong, K.; Jedsadaratanachai, W. Heat transfer enhancement of $\mathrm{TiO}_{2} /$ water nanofluid in a heat exchanger tube equipped with overlapped dual twisted-tapes. Int. J. Eng. Sci. Tech. 2015, 18, 336-350.

8. Sajjad, M.; Kamran, M.S.; Shaukat, R.; Zeinelabdeen, M.I.M. Numerical investigation of laminar convective heat transfer of graphene oxide/ethylene glycol-water nanofluids in a horizontal tube. Int. J. Eng. Sci. Tech. 2018, 21, 727-735.

9. Akinshilo, A.T. Flow and heat transfer of nanofluid with injection through an expanding or contracting porous channel under magnetic force field. Int. J. Eng. Sci. Tech. 2018, 21, 486494.

10. Maheswaran, R.; Sunil, J. Experimental analysis of tribological properties of ultrasonically dispersed garnet nanoparticles in SN500 grade lubricating oil. Ind. Lubr. Tribol. 2018, 70, 250-255.

11. Maheswaran, R.; Sunil, J.; Vettumperumal, R.; Subhash, S.V. Stability Analysis of CuO suspended API GL-5 Gear lubricant sol. J. Mol. Liq. 2018, 249, 617-622.

12. Maheswaran, R.; Sunil, J. Relative anti-wear property evaluation of nano garnet gear lubricant. Int. J. Surf. Sci. Eng. 2017, 11, 320-343.

13. Sunil, J.; Maheswaran, R.; Bavick, P.; Dinesh, K. Synthesis and gravity driven sedimentation study on $\mathrm{ZnS}$-gear lubricant oil nanofluids for gear lubricant applications. Int. J. Chem. Sci. 2016, 14, 1367-1375.

14. Kedzierski, M.A. Viscosity and density of aluminum oxide nanolubricants. Int. J. Refrig. 2013, 36, 1333-1340.

15. Tao, X.; Jiazheng, Z.; Kang, X. The ball-bearing effect of diamond nanoparticles as an oil additive. J. Phys. D 1996, 29, 2932-2937.

16. Kedzierski, M.A.; Brignoli, R.; Quine, K.T.; Brown, J.S. Viscosity, density, and thermal conductivity of aluminum oxide and zinc oxide nanolubricants. Int. J. Refrig. 2016, DOI: http://dx.doi.org/doi: 10.1016/j.ijrefrig.2016.10.003. 
17. Ijam, R.; Saidur, P.; Ganesan, A.; Golsheikh, M. Stability, thermo-physical properties, and electrical conductivity of graphene oxide-deionized water/ethylene glycol based nanofluid. Int. J. Heat Mass Trans. 2015, 87, 92-103.

18. Attari, H.; Derakhshanfard, F.; Darvanjooghi, M.H.K. Effect of temperature and mass fraction on viscosity of crude oil-based nanofluids containing oxide nanoparticles. Int. Commun. Heat Mass Trans. 2017, 82, 103-113.

19. Chen, H.; Ding, Y.; Tan, C. Rheological behaviour of nanofluids. New J. Phys. 2007, 9, 367372.

20. Zhou, J.; Shen, Z.; Liang, Q.; Xu, J.; Liu, H. A new prediction method for the viscosity of the molten coal slag. Part 1: The effect of particle morphology on the suspension viscosity. Fuel 2018, 220, 296-302.

21. Teoh, L.G.; Li, K.D.; Synthesis and characterization of NiO nanoparticles by sol-gel method. Mater. Trans. 2012, 53, 2135-2140.

22. Zorkipli, N.N.M.; Kaus, N.H.M.; Mohamad, A.A. Synthesis of NiO nanoparticles through sol-gel method. Procedia Chem. 2016, 19, 626-631.

23. Yadesa, W.; Taddesse, A.M.; Kibret, K.; Dechassa, N. Synthesis and characterization of FeAl-Mn nanocomposite sorbent for phosphate sorption-desorption study. Bull. Chem. Soc. Ethiop. 2018, 32, 421-436.

24. Ehi-Eromosele, C.O.; Olugbuyirozz, J.A.O.; Taiwo, O.S.; Bamgboye, O.A.; Ango, C.E. Synthesis and evaluation of the antimicrobial potentials of cobalt doped- and magnesium ferrite spinel nanoparticles. Bull. Chem. Soc. Ethiop. 2018, 32, 451-458.

25. Zahedi, N.; Javid, A.; Mohammadi, M.K.; Tavakkoli, H. Microwave-promoted solvent free one-pot synthesis of triazolo[1,2-a] indazole-triones catalyzed by silica-supported $\mathrm{La} 0.5 \mathrm{Ca}$ $0.5 \mathrm{CrO}_{3}$ nanoparticles as a new and reusable perovskite-type oxide. Bull. Chem. Soc. Ethiop. 2018, 32, 239-248.

26. Babadi, N.; Tavakkoli, H.; Afshari, M. Synthesis and characterization of nanocomposite $\mathrm{NiFe}_{2} \mathrm{O}_{4}$ SalenSi and its application in efficient removal of $\mathrm{Ni}(\mathrm{II})$ from aqueous solution. Bull. Chem. Soc. Ethiop. 2018, 32, 77-88.

27. Firuzabadi, F.D.; Asadi, Z.; Yousefi, R. Synthesis of new nano Schiff base complexes: Xray crystallography, thermal, electrochemical and anticancer studies of nano uranyl Schiff base complexes. Bull. Chem. Soc. Ethiop. 2018, 32, 89-100.

28. Habib, N.R.; Taddesse, A.M.; Temesgen, A. Synthesis, characterization and photocatalytic activity of $\mathrm{Mn}_{2} \mathrm{O}_{3} / \mathrm{Al}_{2} \mathrm{O}_{3} / \mathrm{Fe}_{2} \mathrm{O}_{3}$ nanocomposite for degradation of malachite green. Bull. Chem. Soc. Ethiop. 2018, 32, 101-109.

29. Karthikeyan, K.T.; Angulakshmi, V.S.; Karthikeyan, S.; Jothivenkatachalam, K.; Ananda Kumar P.A. Direct growth of vertically aligned carbon nanotubes on silicon substrate by spray pyrolysis of Glycine max oil. Bull. Chem. Soc. Ethiop. 2017, 31(2), 233-240.

30. Ramazani, A.; Shaghaghi, Z.; Aghahosseini, H.; Asiabi, P.A.; Joo, S.W. Silica nanoparticles as a highly efficient catalyst for the one-pot synthesis of sterically congested 2(dibenzylamino)-2-aryl acetamide derivatives from by phthaldehyde isomers, isocyanides and dibenzylamine. Bull. Chem. Soc. Ethiop. 2016, 30, 413-420.

31. Kalpanadevi, K.; Sinduja, C.R.; Manimekalai, R. Synthesis and characterisation of $\mathrm{Ni0} .25 \mathrm{Co} 0.75 \mathrm{Fe}_{2} \mathrm{O}_{4}$ nanostructures. Bull. Chem. Soc. Ethiop. 2016, 30, 79-85.

32. Nibret, A.; Yadav, O.P.; Diaz, I.; Taddesse, A.M. Cr-N co-doped ZnO nanoparticles: Synthesis, characterization and photocatalytic activity for degradation of thymol blue. Bull. Chem. Soc. Ethiop. 2015, 29, 247-258.

33. Vettumperumal, R.; Kalyanaraman, S.; Thangavel, R. Nanocrystalline $\mathrm{Zn}_{1-\mathrm{x}-\mathrm{y}} \mathrm{Be}_{\mathrm{x}} \mathrm{Mg}_{\mathrm{y}} \mathrm{O}$ thin films synthesized by the sol-gel method: structural and near infrared photoluminescence properties. J. Solgel Sci. Technol. 2013, 68, 334-340.

34. Maheswaran, R.; Sunil, J. Effect of nano sized garnet particles dispersion on the viscous behavior of extreme pressure lubricant oil. J. Mol. Liq. 2016, 223, 643-651. 
35. Einstein, A. Investigations on the Theory of the Brownian Movement, Courier Dover Publications: New York; 1956.

36. Hatschek, E. The general theory of viscosity of two phase systems. Trans. Faraday Soc. 1913, 9, 80-92.

37. Batchelor, G.K. The effect of Brownian motion on the bulk stress in a suspension of spherical particles. J. Fluid Mech. 1977, 83, 97-117.

38. Nguyen, C.; Desgranges, F.; Roy, G.; Galanis, N.; Mare, T.; Boucher, S.; Mintsa, H.A. Viscosity data for $\mathrm{Al}_{2} \mathrm{O}_{3}$-water nanofluid-hysteresis: is heat transfer enhancement using nanofluids reliable?. Int. J. Therm. Sci. 2008, 47, 103-111.

39. Wang, X.; Xu, X.; Choi, S.U.S. Thermal conductivity of nanoparticle-fluid mixture. J. Thermophys. Heat Trans. 1999, 13, 474-480.

40. Pak, B.C.; Cho, Y.I. Hydrodynamic and heat transfer study of dispersed fluids with submicron metallic oxide particles. Exp. Heat Transfer. 1998, 11, 151-170.

41. Tseng, W.J.; Lin, K.C. Rheology and colloidal structure of aqueous $\mathrm{TiO}_{2}$ nanoparticle suspensions. Mater. Sci. Eng. A 2003, 335, 186-192.

42. Roscoe, R. The viscosity of suspensions of rigid spheres. Br. J. Appl. Phys. 1952, 3, 267269.

43. Redhwan, A.A.M.; Azmi, W.H.; Sharif, M.Z.; Mamat, R.; Zawawi, N.N.M. Comparative study of thermo-physical properties of $\mathrm{SiO}_{2}$ and $\mathrm{Al}_{2} \mathrm{O}_{3}$ nanoparticles dispersed in PAG lubricant. Appl. Therm. Eng. 2017, 116, 823-832.

44. Nguyen, C.; Desgranges, F.; Roy, G.; Galanis, N.; Mare, T.; Boucher, S. Temperature and particle-size dependent viscosity data for water-based nanofluids - Hysteresis phenomenon. Int. J. Heat Fluid Flow 2007, 28, 1492-1506.

45. Yiamsawas, T.; Mahian, O.; Dalkilic, A.S.; Kaewnai, S.; Wongwises, S. Experimental studies on the viscosity of $\mathrm{TiO}_{2}$ and $\mathrm{Al}_{2} \mathrm{O}_{3}$ nanoparticles suspended in a mixture of ethylene glycol and water for high temperature applications. Appl. Energy 2013, 111, 40-45.

46. Zawawi, N.N.M.; Azmi, W.H.; Redhwan, A.A.M.; Sharif, M.Z.; Sharma, K.V. Thermophysical properties of $\mathrm{Al}_{2} \mathrm{O}_{3}-\mathrm{SiO}_{2} / \mathrm{PAG}$ composite nanolubricant for refrigeration system. Int. J. Refrig. 2017, 80, 1-10.

47. Esfe, M.H.; Rostamian, H.; Sarlak, M.R. A novel study on rheological behavior of ZnOMWCNT/10w40 nanofluid for automotive engines. J. Mol. Liq. 2018, 254, 406-413. 